\title{
Practice and Reformation for Course of Power Electronics Technology Based on "Excellent Engineers Program"
}

\author{
Rui-Ping ZHANG ${ }^{1, a,{ }^{*}}$ and Feng ZHAO ${ }^{1, b}$ \\ ${ }^{1}$ Faculty of Automation and Electrical Engineering, Lanzhou Jiaotong University, Lanzhou, China \\ a153025377@qq.com, b49201319@qq.com
}

Keywords: Power Electronics Technology, Excellent Engineers, Reform of Education, Industry Distinguishing Feature.

\begin{abstract}
To meet the demand of national specialty of Electrical Engineering and the talent training of "Excellent Engineers Program" pilot project, current development of power electronics technology and its application in railway industry are combined. The cultivation of innovative and entrepreneurial talents with strong engineering practice ability was taken as the basic objective, with curriculum contents integrated, thorough researches and practices have been launched from the course teaching method, the implementation and the setting of practice teaching. Anticipated results have been achieved in stimulating students' interest in learning, broadening their knowledge vision and the cultivation of practice and innovation ability.
\end{abstract}

\section{Introduction}

Power Electronics Technology in Lanzhou Jiaotong University, the second batch of National Excellence Engineer Education Training Program University pilot major, started to recruit students since 2012. The school has correspondingly set up a working group of "Excellent Engineers" and a Professional Teaching Committee which involves professors, experts from enterprises and industries to fully implement the conduction of the "Excellent Engineers Program". Relative college personnel have gradually improved the cultivation plan, researches on curriculum system, teaching content and teaching methods have been conducted as well to serve this mission.

The major of Electrical Engineering in our school is a specialty with distinctive railway characteristics, it aims at cultivating talents with basic theory and techniques in Electrical Engineering, Control Science and Engineering and Information Engineering, with specialized knowledge of design, construction, operation and management in electrified rail transit and with strong engineering practice ability and a certain spirit of innovation. Due to the mass application of power electronics technology in electrified railway, the urban rail transit, light rail, subway and high speed railway and EMU ${ }^{[1,2]}$, the Power Electronics Technology course as a multi-disciplinary becomes the core course of practical professional basic education ${ }^{[3]}$. How to combine the application of railway and rail transportation closely, and how to fully embody the feature of the cultivation of innovative talents with engineering practice are the new requirements raised for the teaching of this course in the training of "Excellent Engineers" in electrical engineering specialty with railway characteristics. And how to introduce the relative industry application technology while teaching and to realize the interaction between teaching and practice so that students will get a deeper understanding of the application and recent development in modern power electronics technology related areas, thus inspiring their enthusiasm for follow-up courses, and this in turn becomes the focus of curriculum reformation ${ }^{[45]}$.

Please keep a second copy of your manuscript in your office. When receiving the paper, we assume that the corresponding authors grant us the copyright to use the paper for the book or journal in question. Should authors use tables or figures from other Publications, they must ask the corresponding publishers to grant them the right to publish this material in their paper. 


\section{Basic Processing Route of Curriculum Reformation}

The overall teaching of the curriculum should highlight the main line and put emphasis on the optimization of teaching content and the integration with industry. Additionally, attention should be paid on design of practical teaching and on heuristic education so as to guide students to set up the concept of lifelong learning. According to the required teaching quality of the follow-up course design and graduation design, and based on the reformation and practice experience that the power electronics technology teaching group have obtained during the cultivation of "Excellent Engineers" recent years, the overall idea of the reformation shown in the fig. 1 below has come into being, and this contributes to improving students' ability to apply power electronics technology in industry and will play a critical role in laying a strong foundation for their future work.

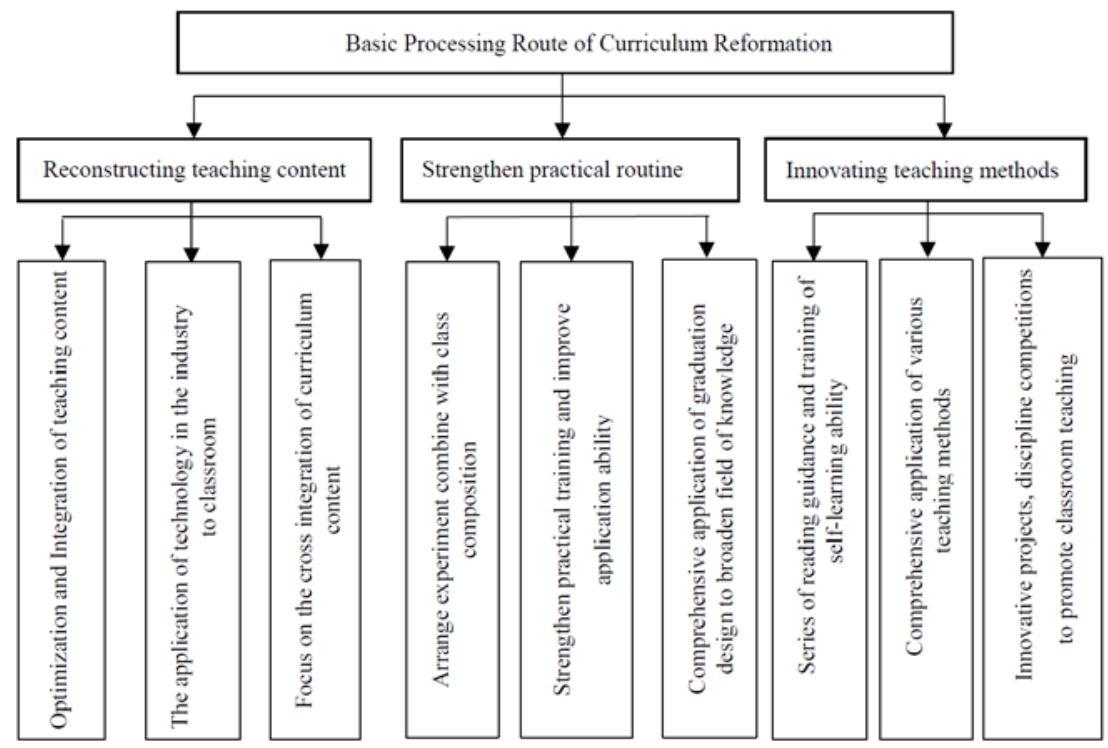

Fig.1 Basic Processing Route of Curriculum Reformation

\section{Reconstructing Teaching Content}

\section{Optimization and Integration of Teaching Content}

There are 48 teaching hours in Power Electronics Technology course, including 42 hours of theory teaching and 6 hours of experiment teaching with two weeks of course design followed. The course mainly introduces control and transformation of electrical energy via power electronic devices, and its content can be divided into three parts that consists of power electronic device, four fundamental forms of transformation of electrical energy and two basic control methods.

According to the feature of the major and industry, the research group sorted up the basic contents and requirements of the course. Taking the four fundamental forms of transformation of electrical energy as the main teaching clue and discussing the teaching contents to clarify the focus of every part of the teaching with the combination of the application and development of the industry. And to make the teaching contents more coherent and systematical, the industry application content has been introduced in each part. It also points out a clear way for students to further develop their learning and system design ability.

The basic nature, main parameter, selection and drive mode of various components are required to be mastered in learning process to lay a solid foundation for the following study and application. And due to its mass utilization of thyristor rectifier device in electric locomotives of electrified railway, subway traction substation and DC transmission in power system, and the PWM Control inverter technology applied in EMU, the selection of nominal parameter of thyristor and IGBT, operating frequency and drive mode are set as main contents to be interpreted. Contents such as the parameters and selection of electric locomotive and thyristor in DC transmission and the application of IGBT in subway and EMU, the application of single-phase rectifying current in electric locomotives and 
application of three phase rectifier circuit in urban rail, subway power supply and power system DC transmission are introduced.

While introducing four fundamental forms of electrical energy conversion and two basic control methods, it is mainly based on the specific application of railway and rail transit, with emphasis on the topology, working principle, waveform analysis and calculation and parameter selection of some circuits. On the basis of the working principle of the circuit and the analysis of the waveform, the harmonic analysis is also highlighted as the key content so as to pave the way for the subsequent harmonic suppression. For instance, in the teaching process of PWM control technology and its application in inverter and rectifier circuit, the PWM control technology and sectional synchronous modulation technology of metro traction inverter, the PWM control technology of wind power generation, photovoltaic generator and converter are introduced.

\section{The Application of Technology in the Industry to Classroom}

The application of the curriculum in industry has been brought into teaching procedure during the optimization and integration of teaching contents. In order to further highlight the characteristics of the application of power electronic technology, professional features are combined to develop students' ability of learning specialized subjects, meanwhile, the school cooperated with enterprises to explore teaching contents with distinct characteristics of railway electrical engineering power electronics technology course.

The application cases of power electronics technology in the rail transit industry have been introduced in teaching of four fundamental electrical energy conversion respectively. For example, while teaching single-phase rectifying circuit the specific application of full control and semi-control bridge rectifier circuit in Shaoshan electric locomotives has been introduced. By analyzing the working process of the bridge rectifier circuit and the power factor of the AC side of the circuit, the three-section equal and unequal division bridge rectifier circuit and their sequential control methods are introduced to improve the power factor of the electric locomotive under different working conditions. By emphasizing the voltage control function that single-phase bridge rectifier circuit plays in the DC power transmission system to enable students to fully understand the characteristics of sequence control methods of this combination circuit, and this method can reduce the maximum withstand voltage of each device while improving the input power factor under the condition of the same output voltage. Analyses and discussions have been conducted to explore the feasibility and operation method of promoting the combination circuit and its control method to high-power converter combination circuit. The combination of single-phase rectifier circuit and voltage and speed adjustment of electric locomotive not only stimulates students' enthusiasm for learning that part, but also promotes students to learn more major related knowledge.

\section{Focus on the cross integration of curriculum content}

The power electronics discipline is an interdisciplinary subject of automatic control theory, power science and electronics. Power electronics technology is not only a technology that uses power electronic devices to transform and control electrical energy, but also a technology to turn "rough

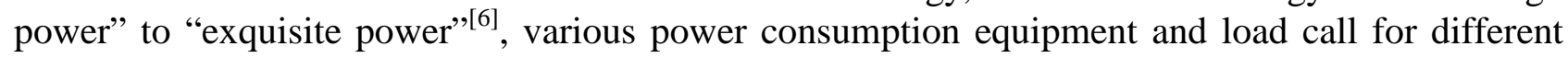
requirements of performance index towards power supply. Emphases should be placed on the cross integration of multiple courses while teaching, and more attention be paid on the seamless connection of teaching, new technology and practical application. Not only should the topology and the control method of power electronics converter be introduced, but sights be set on the power supply requirements that the load of power electronic system calls for, formation of a closed-loop control system by combining various control methods in automatic control theory to further improve the students' ability to integrate their acquired knowledge and their ability to analyze problems and solve problems. 


\section{Strengthen Practical Routine}

\section{Arrange Experiments Combine with Class Composition}

Power Electronics Technology course is a course with strong practical feature. Experimental teaching is an indispensable part of the course which can enhance students' practical ability and make students form perceptual knowledge of components and power electronic system, but there's only three experiments are set up in this course due to the limitation of the Institute's experimental device. The experiments are replication ones mainly set to test and study the performance of the rectifying circuit, DC chopper circuit and AC voltage regulation circuit. Students can get a perceptual understanding of power electronic devices and their basic control methods, but it is far from enough in learning this course. Thus, relative simulation software was introduced to illustrate the construction and simulation of the basic circuit with corresponding assignment being finished.

To make better use of the limited teaching hours, the experiment-related contents were prepared elaborately, and six relative instructions were drafted according to the compulsory experiment plan, with each experiment corresponds to a required and optional part, the latter is an effective supplement to the former one. Experiment contents that represent the latest development of power electronics are added while taking considerations of the requirements of the basic experiment. Some practical engineering techniques are introduced into the experiment content as well to cultivate students' practical practice and engineering application ability.

\section{Strengthen Practical Training and Improve Application Ability}

The curriculum design and the comprehensive training are bound together at the same time. There are two weeks of curriculum design and training procedure in enterprises that lasts four weeks in "Excellent Engineers Program" of electrical engineering. Students are required to acquire relative knowledge by following the mentors from enterprises, and to combine relevant content to complete the curriculum design of related courses over the whole procedure. For example, topics of the design are set according to what the students have learned about high power converter circuits during the visits to generator factories, and the students are required to complete the calculation of the circuit parameters, the selection of the devices, and the construction of the simulation model. Not only has the basic transformation of electric energy been realized by controlling electronic components of the open-loop circuit but also the closed loop control according to the performance index of the circuit, thus, students can comprehend the control and adjustment process of the automatic control theory when the system is disturbed, and the tracking process of output to input can be closely observed. By introducing MCU or DSP course to the overall training to make students understand the specific implementation of controller in simulation process, to improve their ability to apply acquired knowledge comprehensively, and to truly experience the cultivation of excellent engineers.

\section{Comprehensive Application of Graduation Design to Broaden Knowledge Field}

Graduation design is a comprehensive application of acquired knowledge. The wide application of power electronic technology in various industries makes it closely related to various topics of graduation design. Teachers are encouraged to set up R \& D projects in combination with their own scientific research projects during the annual graduation project selection. For competent students, actively guide their autonomous topic selection, we can study the comprehensive application scope of power electronics technology on the basis of their selected topics, and discuss the application of related topics, so as to truly make it a cross discipline while promoting students' self-learning ability. 


\section{Innovating Teaching Methods}

\section{Series of Reading Guidance and Training of Self-Learning Ability}

Besides power electronics technology course, there are so many courses and applications involved in all aspects of the power electronics. Therefore, "teaching" not only reflects teachers' teaching process, but also reflects students' learning process. Teachers are required to arrange certain reference documentation reading and analysis in the teaching process, such as input, output parameters, device parameters, transformer parameters, speed regulation related control and performance indicators, etc. on the electric locomotive.

Additionally, when finishing learning each conversion circuit and teaching of each part, students are required to summarize the advantages and disadvantages of the topology, the analytic method, analysis, contents of calculation, characteristics of harmonic wave and its eliminating methods, and application fields and so on. All of this are dedicated to the cultivation of students' ability of logical thinking and analysis and summary of the problem.

It is also necessary to refer to relative documentation to select topology and control scheme to complete the related design during curriculum design process. Students' ability to consult documentation and materials should be gradually cultivated, meanwhile, their knowledge field be enlarged, thus a solid foundation be laid for their future development.

\section{Comprehensive Application of Various Teaching Methods}

Due to the high dependence of new technology and the continuous compression of the current class hour, how to effectively accomplish the teaching contents in the limited visual range is worth further consideration. Network based course of power electronics technology has been built to make full use of the platform to enrich the teaching resources and show the charm of the course, furthermore, teachers and students can also carry out all aspects of seminars via the platform, forming a favorable support for classroom teaching.

The adoption of heuristic and exploratory teaching method, and by introduction of engineering cases to organize discussions, and layout relative extended thinking operation, thus making the whole teaching process connected with cases, and the requirements of talent cultivation in "Excellent Engineering Program” are truly satisfied.

\section{Innovative Projects, Discipline Competitions to Promote Classroom Teaching}

The cultivation of students' ability of innovation and entrepreneurship is gaining more and more attention, students should be guided to apply relevant innovative experiment project, and through the implementation of the projects, their profound understanding of the course can be guaranteed, and their ability to understand the course be improved, and the interest of self-learning be cultivated during continuous study and discussion.

The students have been showing high enthusiasm for competitions like national electronic design competition, the robot competition, the intelligent car competition and so on. The opportunities should be made full use of to gradually guide students to combine their theoretical knowledge with the competitions closely through documentation reading, conceptual design, simulation experiments, real product making, and to exercise their practical ability and innovative thinking. Particularly, it is necessary to actively guide students to realize the transformation of creativity into products, and to give full play to the mutual promotion of classroom teaching and discipline competition.

\section{Conclusion}

In order to meet the demands of the cultivation of "Excellent Engineering Program”, and starting from the basic goal of the cultivation of innovative talents with strong practical engineering ability, massive work has been done from aspects such as the integration of curriculum, improvement of teaching methods and practice teaching. Every link of curriculum teaching is closely related to training needs, 
and is closely integrated with related applications such as railway and electric power, so that students can understand the application of electrical engineering in rail transit and other aspects, and their interest in learning has been inspired with their horizons been broadened. Related researches have achieved decent results in recent years in the teaching process of theoretical teaching and practice. It has laid a solid foundation for students to engage in related fields such as power electronics.

\section{References}

[1] Wang Zhao’ an, Huang Jun. Power Electronics Technology. China Machine Press, BeiJing, 2005.

[2] Chen Jian. Power Electronics - power electronics transformation and control technology, Second ed, Higher Education Press, Beijing, 2006.

[3] Zhang Hongjuan, Lu Xiufen, Meng Haitao. Teaching Reform on the Engineering Practice of Power Electronic Technology Course. Journal of electrical and electronic teaching, 6(2016) 127-128,132.

[4] Lu Mingli, Liu Yan. Exploration of the teaching reform of the "power electronics technology" course based on the excellent plan. China Electric Power Education, 2(2014) 103-104,108.

[5] Chen Yi, Nan Yurong. Experimental teaching reform with power electronic technology based on introducing guided and innovative mode. experimental technology and management, 34(2017) 103-104,108.

[6] Gao Hanying, Li Wenjuan, Liu Duanzeng. Reform of Teaching and Experiment for Course of Power Electronics Technology. Chinese modern educational equipment, 4 (2016 ): 34-36. 